\title{
A Selective Medium for Pleuropneumonia-like Organisms
}

\author{
By D. G. ff. EDWARD \\ The Wellcome Veterinary Research Station, Frant, Sussex
}

SUMMARY: The action of several bacteriostatic substances on strains of pleuropneumonia-like organisms has been tested. Suitable concentrations of thallium acetate and penicillin in the media were inhibitory for ordinary bacteria, but allowed the pleuropneumonia-like organisms to grow in pure culture and facilitated their primary isolation. These two bacteriostatic substances were also useful for the isolation of strains on plate cultures. The addition of thallium acetate alone to media used for maintaining strains in subculture diminished the number of contaminations.

The media gave variable results, depending on the batch of serum used for enrichment. The routine addition of fresh yeast extract yielded consistently good growths of all strains of pleuropneumonia-like organisms tested. The effective factor in the yeast was not the ' $V$ ' factor required by Pfeiffer's influenza bacillus.

Organisms morphologically and culturally similar to the pathogenic agent of contagious bovine pleuropneumonia have been isolated recently from a number of widely different sources, including the human genital tract (Dienes, 1940; Beveridge, 1943). Failure to recognize this group until lately has been largely due to the peculiar properties of the organisms, especially their exacting cultural requirements, the slowness and paucity of their growth, and the peculiarities of their morphology. Surface colonies are very small and slow to appear and are thus easily overgrown by other organisms. Moreover, certain pleuropneumonia-like organisms associated with infectious catarrh of the upper respiratory tract in mice do not give surface colonies on primary isolation, and can only be isolated by using fluid or semi-solid media (Edward, 1940, 1947). A medium has therefore been sought which would inhibit ordinary bacteria while allowing pleuropneumonia-like organisms to grow in pure culture.

Beveridge (1943) found that pleuropneumonia-like organisms from the human genital tract were relatively resistant to sulphanilamide and used media containing this substance for primary isolation; he also noted growth in media containing gentian violet. The experiments of Powell \& Rice (1944), in which penicillin failed to protect mice against arthritis caused by a pleuropneumonialike organism, suggested that this group might be resistant to penicillin.

\section{Cultural methods}

Basal liquid media were prepared from ox heart infusion broth with $1 \%$ added peptone, adjusted to $\mathrm{pH} 8 \cdot 0$. The basal medium gradually deteriorated on storage and yielded good growths only if used during periods of less than about three months. The final medium, was made by adding $20 \%(\mathrm{v} / \mathrm{v})$ horse serum and $10 \%(\mathrm{v} / \mathrm{v})$ of a yeast extract ( $\equiv 250 \mathrm{~g} . / \mathrm{l}$.$) , with sufficient sterile$ 
caustic soda to bring the final $\mathrm{pH}$ to $8 \cdot 0$. To get rid of precipitable phosphates, broth was prepared in bulk at $\mathrm{pH} 8 \cdot 4$, incubated overnight at $37^{\circ}$ and then Seitz-filtered through a clarifying pad. Finally it was adjusted to $\mathrm{pH} \mathbf{8 . 0}$ and tubed. The yeast extract was prepared by adding $50 \mathrm{~g}$. of brewer's yeast to $200 \mathrm{ml}$. distilled water and boiling until frothing ceased; and was sterilized by Seitz filtration. It was used fresh, but was still suitable after storage in the refrigerator for one week.

Three types of media were used, broth, agar plates and sloppy agar. For solid media $2 \%$ agar (or $1 \%$ New Zealand agar) was added. Sloppy agar $(0 \cdot 3 \%$ agar), introduced by Beveridge (1943), was found particularly useful for the isolation and maintenance of strains. In it the growth of pleuropneumonialike orgainisms varied from a fine granularity, when the inoculum was heavy, to more definite macroscopic colonies, as described by Beveridge. As a routine, stock cultures were maintained in duplicate both in sloppy agars and on plates. For primary isolation of strains capable of giving macroscopic surface colonies, plates had the advantage because colonial appearances of all members of the pleuropneumonia-like group of organisms were so typical that they allowed more rapid and reliable identification.

The L5 organism (Findlay, Klieneberger, MacCallum \& Mackenzie, 1938) and the strains from mouse catarrh were shown to be obligatory aerobes. In sloppy agar they grow only in the upper part of the medium. Growth occurred in an atmosphere of $10 \%$ carbon dioxide in air, but was poor. Strains from the human genital tract grew equally well aerobically, anaerobically and in $10 \%$ carbon dioxide in air.

The 'Yeast Factor'. The use of yeast extract followed the observation that media containing only broth, agar, peptone and horse serum gave variable results depending on the batch of horse serum; sometimes growth was scanty or almost completely absent. Where growth was poor, colonies were larger and more numerous around contaminating colonies of staphylococci. Growth was improved by the addition of freshly prepared filtrates of cultures of these staphylococci. Yeast extract produced a similar enhancement of growth for the L5 organism, strains from mouse catarrh and strains from the human genital tract, but not for the saprophytic sewage organisms of Laidlaw \& Elford (1936). Subsequently yeast extract was added to media as a routine and consistently good growths were obtained.

The factor in the yeast extract necessary for growth withstood heating in the autoclave at $120^{\circ}$ for $60 \mathrm{~min}$; ; it was not destroyed by boiling either at $\mathrm{pH} \mathbf{4 \cdot 2}$ or at $\mathrm{pH} \mathbf{8 \cdot 5}$. Thus the factor was not the ' $\mathrm{V}$ ' factor, coenzymes I or II of Lwoff \& Lwoff (1937). It could not be removed from the extract, nor from a sample of horse serum in which it was abundant, by adsorption on charcoal or by dialysis. Other additions to media used for growing pleuropneumonia-like organisms have been recommended. Klieneberger (1936) used boiled blood and Beveridge (1943) extracts of liver. It appeared that neither of these contained a factor similar to that in yeast, because, when a batch of horse serum was used which needed the addition of yeast extract for growth to occur, it was not possible to obtain growth by replacing the yeast by either of them. 


\section{Action of bacteriostatics}

Several commonly used bacteriostatic substances were tested for their inhibitory action on the L $\mathbf{5}$ organism and on a pleuropneumonia-like organism isolated from mice with catarrh, and also on certain representative bacteria, namely Staph. albus, Staph. aureus, Strep. faecalis, B. subtilis, Bact. coli, Proteus vulgaris and an avirulent diphtheroid organism. The tests were carried out in $10 \mathrm{ml}$. amounts of sloppy agar. Inocula were $0.1 \mathrm{ml}$. of cultures of pleuropneumonia-like organisms in broth or sloppy agar, and one loopful of 1:1000 dilutions of overnight cultures of the bacteria.

Sodium azide at a concentration of $1: 2000$ inhibited the L 5 organism but was not inhibitory at 1:5000; the latter concentration did not prevent growth of any of the representative bacteria (Table 1). Potassium tellurite was markedly inhibitory for $\mathbf{L} \mathbf{5}$, only feeble growth occurring in a concentration of $1: 50,000$. L5 was completely inhibited by $1: 100,000$ brilliant green and by $1: 500,000$ gentian violet; there was feeble growth in $1: 1,000,000$ gentian violet. Neither strain of pleuropneumonia-like organism was inhibited by thallium acetate at concentrations of $1: 1000$ or less, nor by concentrations of penicillin as high as 390 Oxford units $/ \mathrm{mI}$.

Although these tests showed that a medium containing 60 units of penicillin $/ \mathrm{ml}$. prevented growth of all the representative bacteria tested, it seemed likely that strains of aerobic spore-bearing bacilli and non-sporing Gramnegative bacilli with greater resistance to penicillin, or actually able to inactivate it, would sometimes be encountered in practice. Accordingly a selective medium was made containing both penicillin and thallium acetate, the latter being highly bacteriostatic for aerobic spore-bearers and Gram-negative bacilli. The lowest concentration of thallium acetate found to inhibit $P$. vulgaris was $1: 2000$. For Strep. faecalis $60 \mathrm{units} / \mathrm{ml}$. of penicillin was inhibitory, but not 12 units $/ \mathrm{ml}$. The concentrations chosen for use were therefore 1:2000 thallium acetate and about 60 units $/ \mathrm{ml}$. of penicillin. Recently Beveridge, Campbell \& Lind (1946) described the isolation in pure culture of pleuropneumonia-like organisms from the human genital tract in a semi-solid medium containing 20 units of penicillin $/ \mathrm{ml}$.

The value of thallium acetate was shown in the present investigation by inoculating sloppy agars containing 98 units of penicillin/ml. and $1: 2000$ thallium acetate, in parallel with sloppy agars containing penicillin alone, using as inocula material heavily contaminated with sporing and other bacilli, such as dust, bovine faeces, uterine discharges, etc. Bacteria grew out in the media containing penicillin only, but not in those containing penicillin and thallium acetate.

Thallium acetate was made up as a $10 \%$ solution, sterilized by autoclaving and added to the final medium before or after tubing. It was not found necessary to diminish the concentration of sodium chloride in the medium, as suggested by McKenzie (1941). Any precipitate which formed at first subsequently redissolved. ${ }^{-}$In serum agar plates, $1: 2000$ thallium acetate caused 
some degree of inhibition of the pleuropneumonia-like organisms and for plates a concentration of 1:8000 was subsequently used. It is not so essential to have plates completely inhibitory to the ordinary bacteria. Solutions of penicillin (one 10,000 unit tablet dissolved in $1 \mathrm{ml}$. of sterile distilled water and $0.1 \mathrm{ml}$. of the solution added to $10 \mathrm{ml}$. of medium) were freshly prepared and added

Table 1. Action of bacteriostatics on strains of pleuropneumonia-like organisms and on certain representative bacteria

Pleuro-

pneumonia-like

Final concentration of bacteriostatic substance in the medium organisms

Sodium azide:

$1: 2000$

$1: 5000$

$1: 10,000$

Strain

from A diph-

mouse Staph. Staph. Strep. theroid B. sub- Bact. Proteus

L5 catarrh albus aureus faecalis organism tilis coli vulgaris

Potassium tellurite:

$1: 20,000$

$1: 50,000$

-
+

$\begin{array}{lll}\dot{+} & + \\ + & +\end{array}$

$+$

+
+

$\begin{array}{llll}\dot{+} & + & \dot{+} & + \\ + & + & + & +\end{array}$

Thallium acetate:

$1: 500$

$1: 1000$

$1: 2000$

$1: 4000$

$1: 8000$

Gentian violet:

$1: 500,000$

$1: 1,000,000$

(t)

Brilliant green :

$1: 100,000$

Penicillin:

390 units $/ \mathrm{ml}$.

98 units $/ \mathrm{ml}$.

60 units $/ \mathrm{ml}$.

12 units/ml.

$$
\begin{array}{cc}
- & - \\
+ & + \\
+ & + \\
\cdot & \cdot \\
& \cdot \\
& (+) \\
(+) & +
\end{array}
$$

$\cdot \quad \cdot$


failed to grow and the pleuropneumonia-like organisms were recovered in pure culture. A series of tenfold dilutions of a culture of L 5 seeded into bottles of this medium grew as well as in sloppy agars without penicillin or thallium acetate.

Sloppy agars and broths containing thallium acetate and penicillin have been used in approximately 100 attempted isolations of pleuropneumonia-like organisms from the noses of mice and from the human and bovine genital tract, using as inocula material obviously contaminated with bacteria. Only four times have ordinary bacteria grown; on two of these occasions the bacterial load in the inoculum (ox semen) was particularly heavy, and on another occasion the broth only, and not the sloppy agar, grew bacteria. There have been numerous isolations of pleuropneumonia-like organisms in the media from the noses of mice (Edward, 1947) and from the human and bovine genital tract. Unfortunately it was seldom possible to obtain material infected with pleuropneumonia-like organisms but not contaminated with bacteria, in order to compare media with and without bacteriostatics. However, the few observations made did not suggest that the selective media inhibited any of the naturally occurring strains.

Swabs from the human and bovine genital tract were also plated in duplicate on media with and without 1:8000 thallium acetate; half of each plate was spread with penicillin. Several isolations of pleuropneumonia-like organisms were made and there was no evidence of inhibition by penicillin or thallium acetate.

Sloppy agars and plates containing 1:2000 and 1:8000 thallium acetate respectively, without the addition of penicillin, proved useful for the maintenance and examination of stock cultures. Thallium acetate had the advantage over penicillin that it could be added when the media was made and, although it did not inhibit all bacteria, it was bacteriostatic for some of the most troublesome contaminants, such as the aerobic spore-bearing bacilli and Gramnegative bacilli.

I am indebted to Dr E. Klieneberger-Nobel and Dr W. J. Elford for supplying me with strains of pleuropneumonia-like organisms.

\section{REFERENCES}

Beveridge, W. I. B. (1943). Isolation of pleuropneumonia-like organisms from the male urethra. Med. J. Aust. $2,479$.

Beveridge, W. I. B., Campbell, A. D. \& Lind, P. E. (1946). Pleuropneumonia-like organisms in cases of non-gonococcal urethritis in man and in normal female genitalia. Med. J. Aust. $1,179$.

Dienes, L. (1940). Cultivation of pleuropneumonia-like organisms from female genital organs. Proc. Soc. exp. Biol., N.Y., 44, 468.

EDWARD, D. G. ff. (1940). The occurrence in normal mice of pleuropneumonia-like organisms capable of producing pneumonia. J. Path. Bact. 50, 409.

EDward, D. G. ff. (1947). Catarrh of the upper respiratory tract in mice and its association with pleuropneumonia-like organisms. J. Path. Bact. 59, 209. 
Findlay, G. M., Klieneberger, E., MacCallum, F. O. \& Mackenzie, R. D. (1938). Rolling disease. New syndrome in mice associated with a pleuropneumonia-like organism. Lancet, ii, 1511.

KLIENEBerger, E. (1936). Further studies on Streptobacillus moniliformis and its symbiont. J. Path. Bact. 42, 587.

Laidlaw, P. P. \& Elford, W. J. (1936). A new group of filterable organisms. Proc. Roy. Soc. B, 120, 292.

Lwoff, A. \& LwofF, M. (1937). Studies on codehydrogenases. I. Nature of growth factor 'V'. Proc. Roy. Soc. B, 122, 352.

MCKenzie, D. A. (1941). The use of thallium acetate glucose broth in the diagnosis of streptococcal mastitis. Vet. Rec. 53, 473.

Powell, H. M. \& Rice, R. M. (1944). Ineffective penicillin chemotherapy of arthritic rats infected with pleuropneumonia-like organisms. J. Lab. clin. Med. 29, 372.

(Received 30 November 1946) 